\title{
STUDIES ON THE CHEMOTHERAPY OF THE HUMAN MALARIAS. VIII. THE PHYSIOLOGICAL DISPOSITION OF PAMAQUINE $1,2,3$
}

\author{
By CHARLES G. ZUBROD, 4 THOMAS J. KENNEDY, 4 ANd JAMES A. SHANNON \\ (From the Department of Medicine, New York University College of Medicine, and the \\ Research Service, Third [New York University] Medical Division, \\ Goldwater Memorial Hospital, New York City)
}

(Received for publication March 12, 1947)

The recent appreciation $(1,2)$ of the earlier studies on the curative activity of pamaquine in mosquito-transmitted vivax malaria (3) has promoted renewed interest in the chemotherapeutic potentialities of this compound and of several related derivatives of 8 -aminoquinoline. Consequently, a report on the physiological disposition of pamaquine seemed desirable.

\section{METHODS AND MATERIAL}

The individuals used in these studies were, for the most part, patients with central nervous system syphilis. Certain of the pharmacological studies were carried out in normal volunteers. Pamaquine disposition was usually studied prior to induction of therapeutic malaria or after convalescence had become well established. Some of the data on the relationship of dosage ${ }^{5}$ to plasma drug level, however, were obtained during the course of treatment for acute vivax or falciparum malaria. The chemical methods used have been described elsewhere (4).

\section{RESULTS}

\section{Physiological disposition}

A. Absorption. The absorption of pamaquine from the gastro-intestinal tract cannot be examined by balance experiments since the compound

\footnotetext{
1 The work described in this paper was done under a contract, recommended by the Committee on Medical Research, between the Office of Scientific Research and Development and New York University.

$2 \mathrm{~A}$ portion of this work was presented at the meetings of the Federation of American Societies for Experimental Biology, March 11-15, 1946, Federation Proc., 1946, 5, 185.

3 The authors express their thanks to the Malaria Study Section of the National Institute of Health for editorial assistance and for arrangements in regard to the publication of this paper. They are also grateful to the Abbott Laboratories, E. I. du Pont de Nemours and Company, Inc., E. R. Squibb and Sons, Eli Lilly and Company, Sharp and Dohme, and Wyeth, Inc., for contributing toward the publication costs.

4 Captain, MC, AUS.

5 All doses are given in terms of the free base.
}

is rapidly destroyed when incubated at $37^{\circ} \mathrm{C}$. in a suspension of feces. However, indirect evidence of rapid and complete absorption is available from the comparison of curves of the concentration of pamaquine in plasma following single oral and intramuscular doses of the drug (Table I). The

TABLE I

Plasma pamaquine levels three hours after administration of $20 \mathrm{mg}$. (base) of the drug

$\begin{array}{lcc}\text { Patient } & \begin{array}{c}\text { Plasma pamaquine } \\ \text { level after } \\ \text { oral dose } \\ \mu g . / L\end{array} & \begin{array}{c}\text { Plasma pamaquine } \\ \text { level after } \\ \text { intramuscular dose } \\ \text { Sut/L }\end{array} \\ & 64 & 84 \\ & 69 & 84 \\ \text { Des } & 78 & \\ & 75 & 105 \\ \text { Bow } & 112 & 77 \\ & 112 & 91 \\ & 94 & 131 \\ \text { Hur } & 120 & \\ & 121 & 157 \\ & 191 & 170\end{array}$

peak concentration is higher and is reached earlier after intramuscular injection. Yet, at the end of three hours, the concentration is approximately the same, regardless of route of administration. Furthermore, differences in solubility between the various salts of pamaquine do not seem to condition the rate of absorption (Table II).

$B$. Distribution. The distribution of pamaquine in the body has been determined by direct analysis in the dog (Table III). There is some localization of the drug in the liver, lungs and brain, relatively less accumulating in other organs. Indirect evidence of a similar localization in the human was obtained. For example, immediately upon termination of a 15-minute infusion of 20 $\mathrm{mg}$. of the drug, only 5 to 6 per cent can be accounted for in the circulating blood. Such a disappearance cannot be accounted for by metabolism and excretion and must represent localization. 
TABLE II

Plasma pamaquine levels following oral administration of the hydroiodide and naphthoate salts of pamaquine

In each instance the dose furnished $20 \mathrm{mg}$. of the base.

\begin{tabular}{|c|c|c|c|c|}
\hline \multirow{3}{*}{$\underset{\text { (minutes) }}{\text { Time }}$} & \multicolumn{4}{|c|}{$\begin{array}{l}\text { Plasma pamaquine levels } \\
\text { (micrograms per liter) }\end{array}$} \\
\hline & \multicolumn{2}{|c|}{ Patient Sin } & \multicolumn{2}{|c|}{ Patient McK } \\
\hline & Hydroiodide & Naphthoate & Hydroiodide & Naphthoate \\
\hline $\begin{array}{r}30 \\
60 \\
120 \\
180 \\
300 \\
480\end{array}$ & $\begin{array}{r}0 \\
8 \\
97 \\
90\end{array}$ & $\begin{array}{r}4 \\
14 \\
69 \\
69 \\
28 \\
14\end{array}$ & $\begin{array}{r}8 \\
24 \\
42 \\
69\end{array}$ & $\begin{array}{r}3 \\
31 \\
66 \\
69 \\
41 \\
17\end{array}$ \\
\hline
\end{tabular}

C. Excretion. On serial oral dosage of $60 \mathrm{mg}$. daily, about 1 per cent of administered pamaquine was found in the urine of five patients.

D. Metabolism. The pathway of metabolism of the drug is not known. Evidence for the presence of two metabolic intermediates has been obtained from biological fluids of patients receiving pamaquine. These data will be presented in another communication (5). Pamaquine undergoes very rapid metabolic alteration. Eight hours after administration of $20 \mathrm{mg}$. of pamaquine, only negligible amounts can be detected in plasma, and this is not due to marked localization or excretion. However, as will be discussed below, the rate of disappearance from plasma may be greatly modified by quinacrine.

TABLE III

Distribution of pamaquine in the dog

Blood and tissues were obtained for analysis three hours after the dog received a single oral dose of $10 \mathrm{mg}$. per kilo of pamaquine (base) as the hydroiodide.

\begin{tabular}{lcc}
\multicolumn{1}{c}{ Tissue } & $\begin{array}{c}\text { Tissue } \\
\text { pamaquine } \\
\text { concentration } \\
(\mu g . / k i l o)\end{array}$ & $\begin{array}{c}\text { Ratio } \\
\text { tissue pamaquine } \\
\text { concentration to } \\
\text { plasma pamaquine } \\
\text { concentration }\end{array}$ \\
Plasma & 610 & \\
Whole blood & 814 & 1.3 \\
Liver & 22,900 & 37.6 \\
Muscle & 1,360 & 2.2 \\
Brain & 6,460 & 10.6 \\
Spleen & 725 & 1.2 \\
Lung & 15,830 & 26.0 \\
Heart & $3,690$. & 6.0
\end{tabular}

\section{Relationship between dosage and plasma con- centration}

A. Oral dosage. The plasma drug concentrations observed in a series of patients receiving either
30 or $60 \mathrm{mg}$. of pamaquine daily are presented in Table IV. The values in this table represent arithmetic means of plasma drug concentrations obtained just before and three hours after one of the daily doses. The detailed data bear out the suggestion carried in Table II with respect to the rapid rise and fall of plasma drug concentration. When pamaquine is administered at intervals as great as eight hours, peak concentrations are observed two to four hours after each dose, and the minimal concentrations at the end of eight hours are negligible at a daily dosage of $30 \mathrm{mg}$., and very small at $60 \mathrm{mg}$. Such rapid fluctuations in plasma drug concentration may be minimized by administration of divided doses at intervals no longer than four hours. There is a three- to fourfold variation in mean plasma concentration in a group of individuals on the same dosage schedule (Tables I, II and IV).

Occasionally, striking departures of plasma pamaquine concentration from the usual range have been observed. Patient Add, who received $10 \mathrm{mg}$. every four hours, had a mean plasma concentration of $2000 \mu \mathrm{g}$. per liter for the six-day pe-

TABLE IV

Plasma pamaquine levels in a series of individuals receiving pamaquine orally daily in divided doses

The plasma pamaquine levels given below are the means of minimal and maximal plasma drug concentrations. The former is taken just before a dose, the latter three hours after a dose.

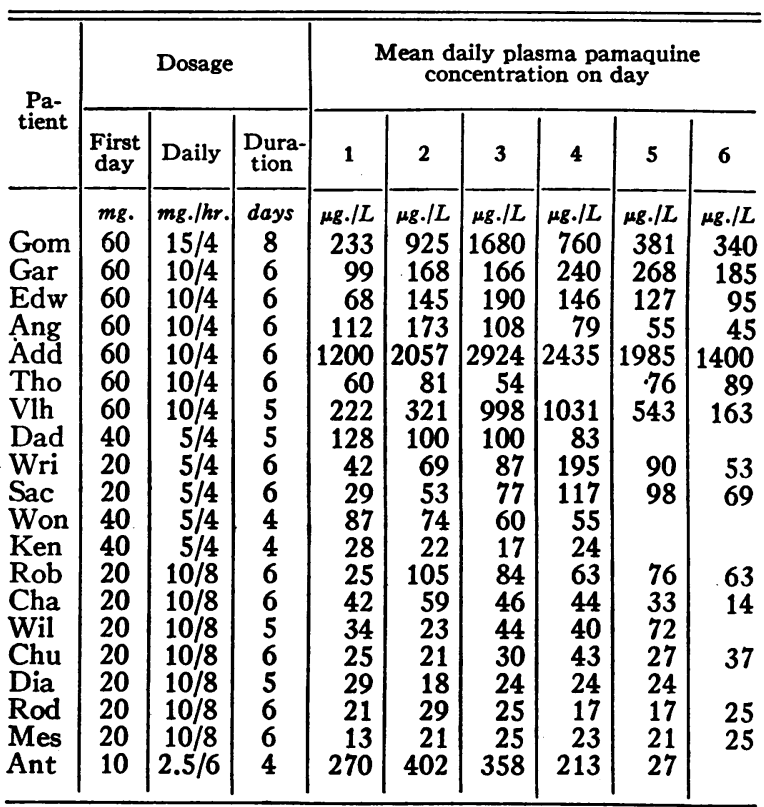


riod and, on the third day, had a level of $2924 \mu \mathrm{g}$. per liter. Patient Vlh, on the same dosage schedule, had a mean plasma concentration of $545 \mu \mathrm{g}$. per liter for the five-day period, and, on days 3 and 4, achieved levels of 1000 and $1030 \mu \mathrm{g}$. per liter respectively. Patient Gom, who received $15 \mathrm{mg}$. every four hours for eight days, reached plasma drug concentrations of 925,1680 and $760 \mu \mathrm{g}$. per liter on days 2,3 , and 4 respectively, with levels in the expected range on the other days of the period. One patient, receiving only $2.5 \mathrm{mg}$. every six hours for four days, had a mean drug concentration for the four-day period of $313 \mu \mathrm{g}$. per liter and, on one day, had a level of $402 \mu \mathrm{g}$. per liter.

Instances such as these were exceptional and were not due to prior or concurrent quinacrine therapy (vide infra). These patients were receiving no medication other than pamaquine.

$B$. Intramuscular dosage. Following the intramuscular administration of $20-\mathrm{mg}$. doses of pamaquine the maximum concentration in plasma was reached earlier than was the case after oral administration, usually in from 30 to 60 minutes, and was higher, ranging from 200 to $400 \mu \mathrm{g}$. per liter. At the end of three hours and thereafter, however, the plasma drug concentration was approximately the same as when the oral route was employed (Table I). Variability in plasma pamaquine concentration from patient to patient was noted after intramuscular as well as after oral administration. As in the case of orally adminis-

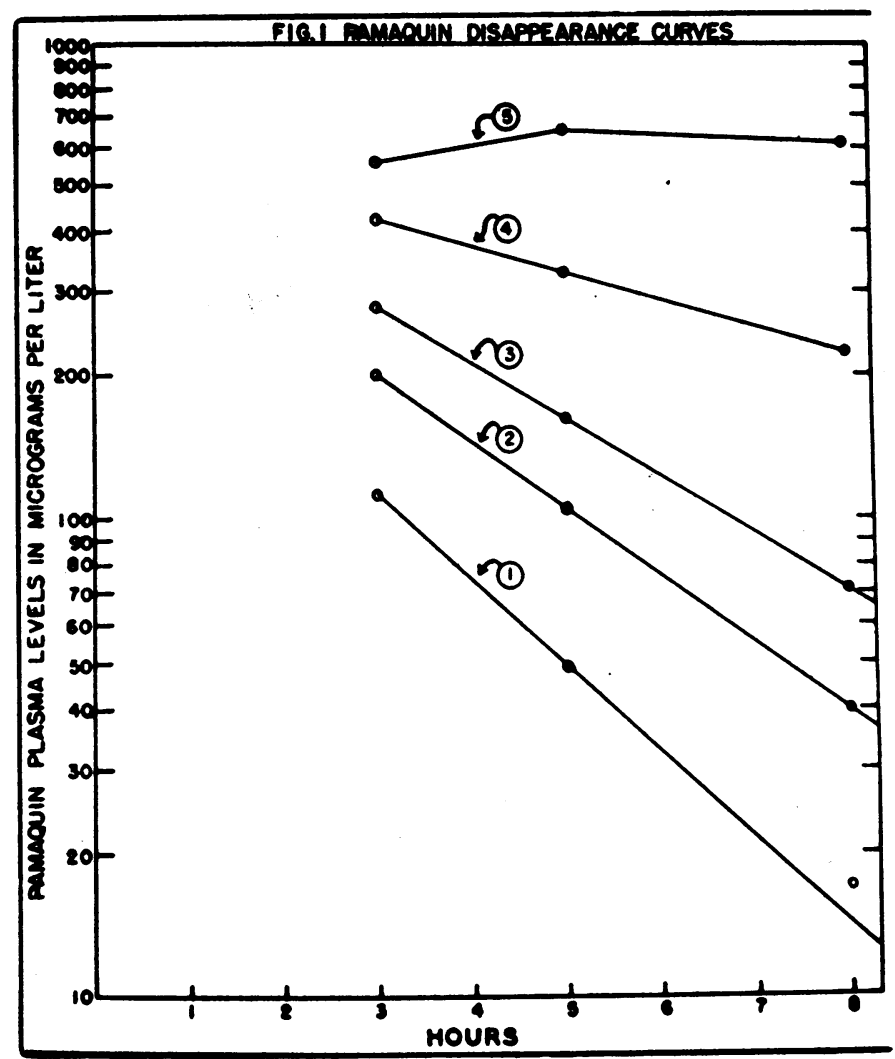

Fig. 1. Effect of 10 Mg. Quinacrine Every Eight Hours for Eight Doses on Plasma Pamaquine Curves Following Single Oral Doses of 20 mg. Pamaquine (Base)

Curve 1 = control ; curve 2 = ten hours after first dose of quinacrine; curve $3=$ one day after first dose; curve $4=$ four days; curve $5=$ eight days. 
tered drug, plasma pamaquine concentration curves were reproducible in any individual when serial studies were made.

\section{Modification of physiological disposition of pamaquine by other drugs}

A. Quinacrine. Among individuals who acheived and maintained unusually high plasma pamaquine concentrations, the majority had previously received quinacrine. Systematic studies to determine whether quinacrine was causally related to the abnormal plasma pamaquine levels were carried out. This study was simplified by the fact that in any individual, the curve of plasma drug concentration was reproducible following standard 20-mg. doses of pamaquine.

Plasma pamaquine curves determined in the same individual before and after receiving various doses of quinacrine (Table V) showed that (1) the maximal plasma pamaquine concentrations are many times higher following quinacrine therapy than the control values and (2) the rate of disappearance is markedly reduced, as shown by the time necessary for the disappearance of $\mathbf{5 0}$ per cent of the maximum concentration (Table V).
TABLE V

Effect of quinacrine on plasma pamaquine levels after single oral doses of $20 \mathrm{mg}$. of pamaquine (base)

\begin{tabular}{|c|c|c|c|c|c|}
\hline \multirow{2}{*}{ Patient } & \multirow{2}{*}{$\begin{array}{c}\text { Quina- } \\
\text { crine } \\
\text { prior } \\
\text { to } \\
\text { observa- } \\
\text { tion }\end{array}$} & \multicolumn{2}{|c|}{$\begin{array}{l}\text { Maximum plasma } \\
\text { pamaquine level }\end{array}$} & \multicolumn{2}{|c|}{$\begin{array}{l}\text { Time for } 50 \% \text { dis- } \\
\text { appearance }\end{array}$} \\
\hline & & Control & $\begin{array}{l}\text { After } \\
\text { quina- } \\
\text { crine }\end{array}$ & Control & $\begin{array}{c}\text { After } \\
\text { quina- } \\
\text { crine }\end{array}$ \\
\hline $\begin{array}{l}\mathrm{To} \\
\mathrm{Bo} \\
\mathrm{Ke} \\
\mathrm{Ai}\end{array}$ & $\begin{array}{c}\text { grams } \\
2.5 \\
2.0 \\
0.5 \\
1.4\end{array}$ & $\begin{array}{r}\mu g . / L \\
112 \\
62 \\
63 \\
86\end{array}$ & $\begin{array}{c}\mu g . / L \\
660 \\
575 \\
425 \\
605\end{array}$ & $\begin{array}{c}\text { hours } \\
1.7 \\
2.0 \\
1.8 \\
3.0\end{array}$ & $\begin{array}{r}\text { hours } \\
23.0 \\
7.7 \\
8.1 \\
5.2\end{array}$ \\
\hline
\end{tabular}

In Figure 1, the control curve, number 1, and a series of curves performed in the order numbered at various intervals after initiation of quinacrine administration to patient To, are plotted. This figure shows both progressive upward displacement of the maximum and progressive retardation of the rate of disappearance after quinacrine was administered. The three other patients who were subjected to this type of study had curves in which similar changes were induced by quinacrine administration. Very small amounts of quinacrine are capable of producing this phenomenon. Curve number 2 of Figure 1 was performed ten hours after the first dose $(20 \mathrm{mg}$.) of quinacrine, yet the

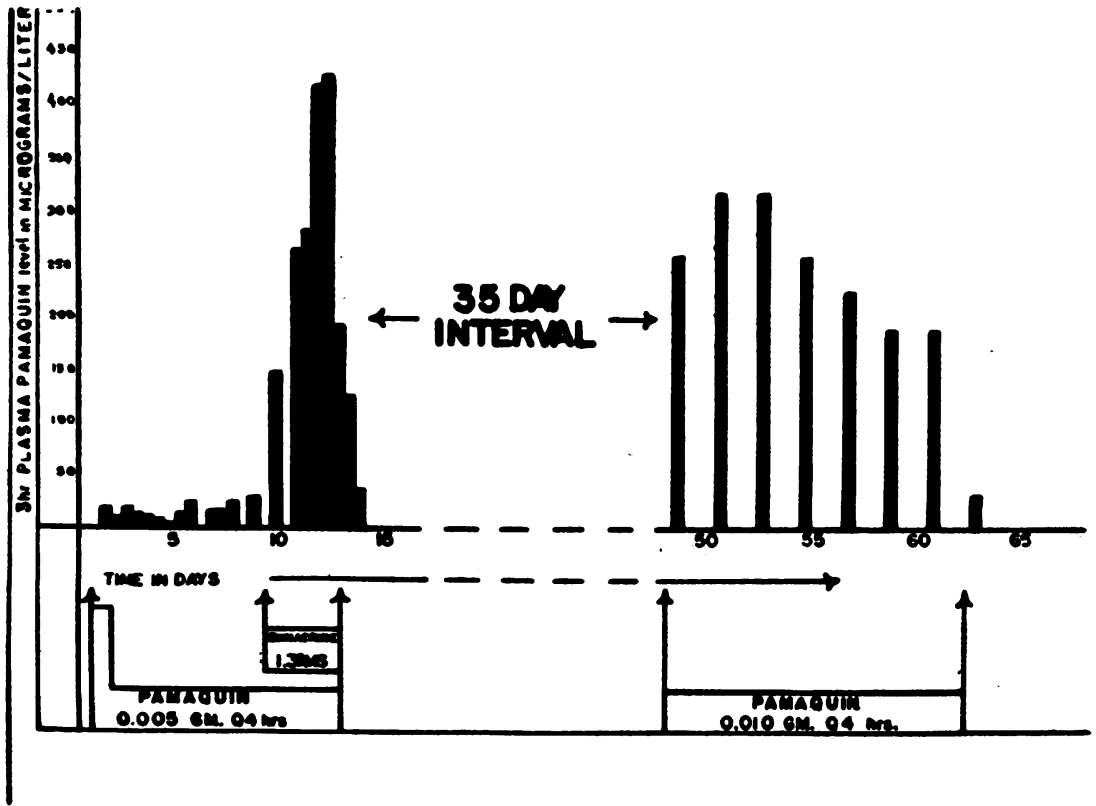

Fig. 2. Effect of Quinacrine Administration on Mean Plasma Pamaquine Levels Resulting from Serial Oral Doses of Pamaquine 
maximum has been doubled and the rate of disappearance retarded.

It is well known that quinacrine disappears slowly from the body. It would seem reasonable, therefore, to predict that the ability of quinacrine to modify pamaquine metabolism would not be an evanescent phenomenon. Daily pamaquine levels three hours after the 6 a.m. dose in an individual on constant pamaquine intake of $30 \mathrm{mg}$. daily are shown in Figure 2. During the control period, the daily plasma pamaquine levels averaged $40 \mu \mathrm{g}$. per liter. During a period when $30 \mathrm{mg}$. of quinacrine was also administered daily, the plasma pamaquine levels were greatly elevated, reaching as high as $450 \mu \mathrm{g}$. per liter. After a medicationfree interval of 35 days, resumption of a slightly higher constant pamaquine dosage regimen resulted in plasma drug levels far in excess of the usual range and not explainable on the basis of increased dosage. Such effects have been observed as long as three months following the last dose of quinacrine in many patients.

Mean plasma pamaquine concentrations in four patients who received concurrently $30 \mathrm{mg}$. of pamaquine and $300 \mathrm{mg}$. of quinacrine daily were 100 per cent higher than the mean levels of patients who received $90 \mathrm{mg}$. of pamaquine and 2.0 gm. of quinine daily.

In none of these experiments were there any significant deviations of plasma quinacrine concentration from the expected levels.

$B$. Quinine. The effect of concurrent administration of quinine on plasma pamaquine concentration was investigated by experiments similar to those which demonstrate the effect of quinacrine. When concentration curves of pamaquine in plasma were studied in individuals before and during quinine administration, no significant alteration of either the height or the form of the curve was observed. These curves were analyzed after oral pamaquine administration in six cases, after intramuscular, in four cases, and after intravenous, in one case.

The introduction of quinine into the dosage regimen of individuals receiving $30 \mathrm{mg}$. of pamaquine daily was studied to determine whether the three-hour plasma pamaquine level was affected. In three cases there was a slight but probably significant rise in the plasma pamaquine concentration during the period of concurrent quinine administration, while in one case, the plasma pamaquine level was not significantly changed. Analysis of the data collected from routinely determined plasma drug concentrations in individuals receiving quinine and pamaquine simultaneously for treatment of vivax malaria showed no constant relationship between the plasma concentration of one drug and that of the other.

The data collected in this laboratory do not permit a definitive answer to the question of the effect of quinine on pamaquine plasma concentrations. It can be said, however, that quinine does not have as marked an effect as does quinacrine, and that in all probability its effect, if it exists, will be demonstrated only by statistical analysis of a large body of well-controlled data.

C. Chloroquine. Very little information is available on the effect of chloroquine on pamaquine metabolism. However, no striking elevations of pamaquine plasma concentration have been observed after chloroquine administration.

\section{DISCUSSION}

The plasma pamaquine concentration on any given dosage is determined for the most part by localization and metabolic conversion, since its excretion is minimal and absorption is probably rapid and complete.

As evidence for localization, the computation of a "volume of distribution" for a compound such as this, which is subject not only to the process of localization, but also to that of metabolic alteration, is of limited value. The strongest evidence in favor of pamaquine localization in man is that only 6 per cent of the drug can be found in the circulating blood shortly after intravenous infusion. Since neither excretion nor metabolism seems to be rapid enough to dispose of 95 per cent of the drug in the time available, it is reasonable to assume that a large proportion of it has been localized. This is confirmed by the distribution studies in the dog.

The early high peak of 200-400 $\mu$ g. per liter in 30-60 minutes after intramuscular injection of pamaquine differs considerably from the lower peaks of 100-200 $\mu \mathrm{g}$. per liter in two to three hours after the drug is administered by mouth. This difference is probably ascribable more to the rate of absorption than to any other factor. The variability in mean plasma concentration achieved 
within a group of individuals receiving the same dosage of drug is of interest. If this difference were due entirely to variation in the rate of metabolic conversion, it would be expected that the most rapid rates of disappearance of pamaquine from plasma would be found in those individuals who achieved low plasma drug concentrations and, conversely, the slowest rates of disappearance in those who achieved the highest three-hour concentrations. However, on analysis of the disappearance curves of pamaquine from plasma, there was no relation between the height of the peak (or the three-hour concentration) and the rate of disappearance from plasma. Some of those with very high peaks had a rapid rate of disappearance while in some with low peaks the rate of disappearance was quite slow. These observations suggest that localization rather than metabolism is the factor which explains the observed variability.

However, the rapid disappearance of pamaquine from the body is indicative of the importance of the process of metabolic alteration. Study of the pathway of metabolism and of the metabolic products of pamaquine may yield results of practical as well as theoretical interest. In the curative treatment of mosquito-induced vivax malaria (1) no relationship was observed between the mean plasma concentration of the substance measured by the analytical method described, and the clinical effect (cure or relapse). This observation suggests that a metabolic derivative not measured by the reaction with diazotized sulfanilic acid may be the curative agent.

The modification by quinacrine of pamaquine plasma concentration is a striking phenomenon in which both localization and metabolism are probably altered. The very small amount of the acridine capable of excluding pamaquine from sites of localization and/or metabolic channels suggests that quinacrine has a greater affinity for the affected system than has pamaquine.

It has been said for many years that pamaquine toxicity is enhanced by concurrent quinacrine administration. Data presented in another paper (6) support this statement as far as leukopenia and methemoglobinemia are concerned. It is, therefore, proposed that the modification of pamaquine disposition effected by quinacrine represents a specific example of a mechanism whereby one drug (quinacrine) potentiates the activity (toxic) of another (pamaquine).

Although quinine does not modify pamaquine disposition in as obvious a fashion as does quinacrine, there is little doubt that quinine potentiates the curative action of pamaquine. While neither compound alone is capable of preventing relapses of mosquito-induced vivax malaria with any degree of regularity, a high percentage of cures can be obtained by simultaneous administration of both drugs $(1,7,8)$. Moreover, it has been shown that the combination of drugs exerts an effect on hemoglobin metabolism not observed when the drugs are administered separately (9).

\section{CONCLUSIONS}

1. Evidence, for the most part indirect, indicates rapid and complete absorption of pamaquine from the gastro-intestinal tract.

2. By direct analysis, in the dog, moderate degrees of localization in liver, lung and brain were demonstrated. Presumably, substantially the same situation obtains in man.

3. Urinary excretion of pamaquine is very small ( 1 per cent) in the dosage range studied.

4. Disposal of the drug is almost entirely by metabolic alteration. This proceeds at a rapid rate, since eight to 12 hours suffice for the disappearance of $60-\mathrm{mg}$. doses.

5. The relationship between oral and intramuscular dosage and resulting plasma pamaquine concentration is presented.

6. Quinacrine inhibits the metabolic alteration and possibly the localization of pamaquine.

\section{BIBLIOGRAPHY}

1. Berliner, R. W., Earle, D. P., Jr., Taggart, J. V., Welch, W. J., Zubrod, C. G., Knowlton, P., Atchley, J. A., and Shannon, J. A., Studies on the chemotherapy of the human malarias. VII. The antimalarial activity of pamaquine. J. Clin. Invest., 1948, 27, Suppl., 108.

2. Thomson, A. M., and Williams, M. W., Treatment of malaria. Lancet, 1945, 2, 249.

3. Sinton, J. A., Smith, S., and Pottinger, D., Studies in malaria with special reference to treatment; further researches into the treatment of chronic benign tertian malaria with Plasmoquine and Quinine. Indian J. M. Research, 1929-30, 17, 793.

4. Brodie, B. B., Udenfriend, S., and Taggart, J. V., The estimation of basic organic compounds in 
biological fluids. IV. Estimation by coupling with diazonium salts. J. Biol. Chem., 1947, 168, 327.

5. Brodie, B. B., In preparation.

6. Earle, D. P., Jr., Bigelow, F. S., Zubrod, C. G., and Kane, C. A., Studies on the chemotherapy of the human malarias. IX. Effect of pamaquine on the blood cells of man. J. Clin. Invest., 1948, 27, Suppl., 121.

7. Ruhe, D. S., Cooper, W. C., Coatney, G. R., and Josephson, E. S., Studies in human malaria. XV.
The therapeutic action of pamaquine ( $S N-971)$ against St. Elizabeth strain vivax malaria. Am. J. Hyg. To be published.

8. Alving, A. S., Pullman, T. N., Craige, B., Jr., Jones, R., Jr., Whorton, C. M., and Eichelberger, L., The clinical trial of 18 analogues of pamaquine (plasmochin) in vivax malaria (Chesson strain). J. Clin. Invest., 1948, 27, Suppl., 34.

9. Blake, W. D., Methemalbumin. II. Effect of pamaquine and quinine on pathways of hemoglobin metabolism. J. Clin. Invest., 1948, 27, Suppl., 144. 